\title{
Pengaruh Budaya Organisasi Islami terhadap Efektivitas Organisasi (Studi pada Rumah Sakit Syariah Kab Sumedang)
}

\author{
Oleh: \\ Allya Roosallyn Assyofa ${ }^{1}$, Mochamad Malik Akbar Rohandi ${ }^{2}$, Shania Antony Putri ${ }^{3}$ \\ ${ }^{1-3}$ Fakultas Ekonomi dan Bisnis-Manajemen, Universitas Islam Bandung (Unisba) \\ E-mail: ${ }^{1}$ roosallyn.allya@gmail.com, ${ }^{2}$ moch.malik@gmail.com, ${ }^{3}$ shanianaya60@gmail.com
}

\begin{abstract}
ABSTRAK
Makalah ini mencoba untuk menginvestigasi hubungan antara budaya organisasi dan efektivitas organisasi dari perspektif Islam di rumah sakit. Budaya organisasi dan keefektifan organisasi telah memperoleh banyak popularitas dan sejumlah besar diskusi di kalangan pengusaha dan memang menarik minat para peneliti. Berbagai penelitian menunjukkan bahwa ada kebutuhan untuk fokus pada penelitian yang secara holistik mencakup masalah yang paling signifikan dari subjek. Oleh karena itu, bertujuan untuk mengisi kesenjangan ini, penelitian ini mengusulkan kerangka kerja konseptual untuk memahami pengaruh budaya organisasi terhadap efektivitas organisasi. Selain itu, penelitian ini juga menyarankan adopsi budaya organisasi dari Perspektif Islam karena merupakan salah satu faktor penting dalam menghasilkan lingkungan yang ideal yang memupuk yang terbaik dari karyawan dan organisasi, dan komitmen dan pengalaman orang-orang di dalamnya. Pertama, konsep budaya organisasi dan efektivitas organisasi dibahas secara singkat. Kemudian, analisis untuk penelitian disajikan. Penelitian ini menggunakan metode kuantitatif melalui survei eksplanatori. Penelitian ini menghasilkan bahwa budaya organisasi dari perspektif Islam mengandung As suluk Al fardi (Perilaku Individu), As suluk Al jama'i (perilaku Inter-individu), dan As suluk Al mudir (perilaku manajerial) secara signifikan terkait dengan efektivitas organisasi.
\end{abstract}

Kata Kunci: Budaya Organisasi Islami, Budaya Organisasi, Efektivitas Organisasi, Rumah Sakit Syariah

\begin{abstract}
This paper attempts to investigate the relationships between organizational culture and organizational effectivity from Islamic perspective on a hospital. Organizational culture and organizational effectivity have gained much popularity and a considerable amount of discussions among employers and indeed is of escalating interest to researchers. Various research suggested that there is a need to focus on research that holistically cover the most significant issues of the subject. Therefore, aiming to fill this gap, this study proposes a conceptual framework to understand the effect of organizational culture on organizational effectivity. In addition, this study also suggests the adoption of organizational culture from Islamic Perspective as it is one of the critical factors in producing an ideal environment which cultivates the best out of employees and organizations, and the commitment and experiences of the people in it. First, the concepts of organizational culture and organizational effectivity are briefly discussed. Then, the analysis for the study is presented. This study use a quantitative method through explanatory survey. This study results that organizational culture from Islamic perspective contains of As suluk Al fardi (Individual Behavior), As suluk Al jama'i (Inter-individual behavior), and As suluk Al mudir (managerial behavior) is significantly related to organizational effectiveness.
\end{abstract}

Keywords: Islamic organizational culture, organizational culture, organizational effectivity, sharia hospital 


\section{I.PENDAHULUAN}

\subsection{Latar Belakang}

Rumah Sakit Syariah Kab Sumedang (RS Syariah Kab Sumedang) merupakan salah satu rumah sakit di wilayah Kabupaten Sumedang yang memiliki visi kedepan sebagai RSU Syariah pertama di wilayahnya. Terdapat hal-hal yang membedakan antara organisasi Islam dengan organisasi non Islam, setidaknya ada 4 hal yang menjadi perhatian khusus, pertama akad kerja sama yang didasarkan pada prinsip-prinsip islam; organisasi diatur dengan mekanisme produksi Islami; pencatatan dan kebijakan akuntansi dan keuangan berbasis prinsip Islam; dan budaya perusahaan yang tercermin dalam performa perusahaan menunjukkan citra keislaman. Keseluruhannya tidak terlepas dari segitiga dasar yang meliputi akidah, syariah dan akhlak. Performa yang baik dan tampak Islami tidak menjamin pemahaman akan ketauhidan yang baik dan ketaatan aturan syariah yang baik (Adityangga, 2010).

Budaya perusahaan islami yang baik dapat menciptakan brand image tersendiri bagi RS Syariah Kab Sumedang, penerapan budaya ini akan mendorong dan menekan para stakeholder yang berada didalamnya untuk berbuat yang sesuai dengan prinsip-prinsip islam berasaskan Al Quran dan Hadist serta ijma' dan ijtihad para ulama. Bila para stakeholder internal telah memiliki akhlak Al Quran maka secara tidak langsung dapat memberikan pengaruh kepada para pasien yang menggunakan jasa dari RS Syariah Kab Sumedang dan diharapkan terjadinya Word Of Mouth (WOM) positif dari hal tersebut yang akan berdampak pada peningkatan kesadaran pasien untuk menggunakan jasa RS Islam.

\subsection{Identifikasi Masalah}

Berdasarkan latar belakang diatas, identifikasi masalah dalam penelitian ini adalah belum diketahui apakah RS Syariah Kab Sumedang sebagai rumah sakit yang bertujuan utama memberikan pelayanan kesehatan kepada masyarakat dan membawa nama Islam dalam budaya organisasi dan kegiatan sehari-harinya sudah sesuai dengan nilai-nilai Islami yang diusung dalam corporate value nya.

\subsection{Rumusan Masalah}

Berdasarkan latar belakang diatas, dapat dirumuskan masalah dalam penelitian ini yaitu :

1. Bagaimana nilai-nilai Islam yang terkandung dalam budaya organisasi RS Syariah Kab Sumedang?

2. Bagaimana penerapan dan penanaman (internalisasi) nilai-nilai Islami perusahaan pada karyawan RS Syariah Kab Sumedang?

3. Bagaimana efektivitas penerapan budaya perusahaan secara keseluruhan pada RS Syariah Kab Sumedang?

\section{LANDASAN TEORI}

\subsection{Budaya Organisasi Islami}

Budaya organisasi merupakan konsep yang mendorong orang dalam sebuah organisasi untuk bertindak sebagai satu kesatuan. Dengan kata lain konsep ini juga berarti 
semua perbuatan, kebiasaan, adat dan bahasa yang mengikat orang bersama-sama dalam sebuah organisasi (Khaliq Ahmad,2007). Pada organisasi yang tidak berlandaskan Islam, faktor penggerak karyawan untuk bekerja biasanya sebagai berikut;

- Keinginan akan laba

- Promosi demi kepentingan sendiri

Pada organisasi yang berlandaskan Islam, budaya organisasi harus didasarkan pada hal-hal sebagai berikut:

a. Tauhid dan implikasinya terhadap manusia, yaitu dalam hal memandang pekerjaan sebagai ibadah dan usaha membangun Islam

"Apabila Telah ditunaikan shalat, maka menyebarlah di bumi dan carilah karunia Allah dan ingatlah Allah banyak-banyak supaya kamu beruntung." (QS. Al-Jum "ah: 10)

b. Ukhuwah Islamiyah (persaudaraan Islami)

"Sesungguhnya orang-orang mukmin itu bersaudara" (QS. AlHujurat: 10)

c. Pedoman sosial Islami, seperti tidak memfitnah, tidak menyebarkan rumor dan berbuat jahat

"Dan janganlah kamu membuat kerusakan di muka bumi, sesudah (Allah) memperbaikinya dan berdoalah kepada-Nya dengan rasa takut (tidak akan diterima) dan harapan (akan dikabulkan). Sesungguhnya rahmat Allah amat dekat kepada orang-orang yang berbuat baik." (QS. Al A'raf : 56)

d. Peningkatan kemampuan Islami pada karyawan, contohnya pelatihan dan peningkatan pengetahuan serta kemampuan lainnya

"Tidak sepatutnya bagi mukminin itu pergi semuanya (ke medan perang). mengapa tidak pergi dari tiap-tiap golongan di antara mereka beberapa orang untuk memperdalam pengetahuan mereka tentang agama dan untuk memberi peringatan kepada kaumnya apabila mereka telah kembali kepadanya, supaya mereka itu dapat menjaga dirinya." (QS. At Taubah : 122)

Budaya organisasi atau budaya korporat Islami adalah budaya organisasi yang berdasarkan nilai-nilai yang disepakati dalam Islam. Nilai-nilai itu haruslah diambil dari sumber-sumber hukum Islam yaitu Al Quran dan hadist Rasulullah SAW. Sumber dasar ini kemudian dijabarkan melalui struktur yang berlandaskan konsep pelimpahan wewenang yang bersumber dari Allah dengan keterampilan yang pantas sebagai khalifatullah fil 'ard (pemimpin di muka bumi).

Sistemnya berpegang pada dua tali yaitu vertikal kepada Allah dan horizontal kepada sesama manusia dengan satu arahan untuk mencapai sasaran dengan strategi amr ma'ruf nahy munkar (Adnanputra, 1999). Alamsyah (2002) mengatakan bahwa perilaku suatu organisasi Islami yang bernafaskan Islam bisa beragam namun muncul dari sesuatu yang sama. Semuanya berawal dari hakikat nafsu manusia (haqiqotul nafsun insaniyah) yang muncul dalam bentuk akhlak Islamiyah (akhlaqul islamiyah).

Perilaku organisasi kemudian terbagi menjadi 3 bagian yaitu: perilaku individu anggota organisasi (As suluk al fardi), perilaku antar individu (As suluk al jama"i), dan perilaku manajerial/kepemimpinan (As suluk al mudir). Seluruh perubahan baik organisasi maupun negara haruslah dimulai dari perubahan individu. Membentuk budaya organisasi yang islami tidak lain adalah dengan merubah individu-individu didalamnya menjadi lebih islami. Inilah hal pertama yang menuntut adanya usaha terus menerus secara berkesinambungan. 


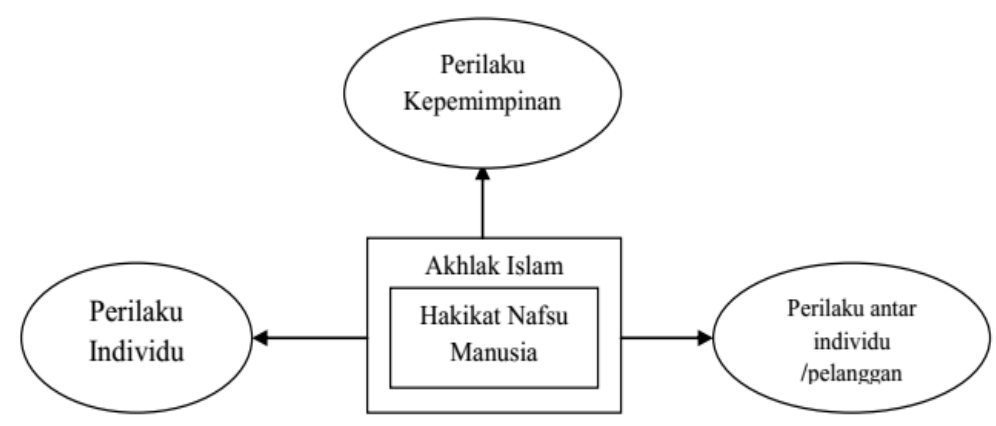

Gambar 2.1 Model nilai dan Perilaku Organisasi Islam

Sumber: (Alamsyah,2000)

\subsection{Efektivitas Organisasi}

Efektivitas berarti kemampuan menghasilkan efek, dan yang paling sering digunakan dalam kaitannya dengan sejauh mana sesuatu yang mampu menghasilkan yang diinginkan. Dalam manajemen, efektivitas berkaitan dengan hal yang benar terlaksana. Robbins (1994:54) mengungkapkan juga mengenai pendekatan dalam efektivitas organisasi:

a) Pendekatan pencapaian tujuan (goal attainment approach). Pendekatan ini memandang bahwa keefektifan organisasi dapat dilihat dari pencapaian tujuannya (ends) daripada caranya (means). Kriteria pendekatan yang popular digunakan adalah memaksimalkan laba, memenangkan persaingan dan lain sebagainya. Metode manajemen yang terkait dengan pendekatan ini dikenal dengan Management By Objectives (MBO) yaitu falsafah manajemen yang menilai keefektifan organisasi dan anggotanya dengan cara menilai seberapa jauh mereka mencapai tujuan-tujuan yang telah ditetapkan.

b) Pendekatan sistem. Pendekatan ini menekankan bahwa untuk meningkatkan kelangsungan hidup organisasi, maka yang perlu diperhatikan adalah sumber daya manusianya, mempertahankan diri secara internal dan memperbaiki struktur organisasi dan pemanfaatan teknologi agar dapat berintegrasi dengan lingkungan.

c) Pendekatan konstituensi-strategis. Pendekatan ini menekankan pada pemenuhan tuntutan konstituensi itu di dalam lingkungan yang darinya orang tersebut memerlukan dukungan yang terus menerus bagi kelangsungan hidupnya.

d) Pendekatan nilai-nilai bersaing. Pendekatan ini mencoba mempersatukan ketiga pendekatan di atas, masing-masing didasarkan atas suatu kelompok nilai. Masing-masing nilai selanjutnya lebih disukai berdasarkan daur hidup di mana organisasi itu berada.

\section{METODE PENELITIAN}

Penelitian ini menggunakan metode Kuantitatif untuk memberikan informasi yang tepat berdasarkan data faktual yang terjadi di perusahaan. Metode survey eksplanatori digunakan dengan tujuan untuk menguji hubungan dua variabel atau lebih, dalam hal ini variabel independennya adalah budaya organisasi islami dan efektifitas kerja. Penelitian ini menggunakan penelitian deskriptif untuk menggambarkan keadaan-keadaan yang mungkin terdapat dalam situasi tertentu.

Objek dalam penelitian ini adalah RS Syariah Kab Sumedang, penentuan jumlah sampel dilakukan dengan menggunakan probability sampling secara random sampling, total populasi organisasi sebesar 147 (seratus empat puluh tujuh) orang, jumlah sampel minimum 
berdasarkan metode slovin dengan tingkat error 10\% adalah 60 (enam puluh) orang. Kuesioner yang kembali berjumlah 66 (enam puluh enam) sehingga data yang terkumpul dapat dilakukan pengolahan.

Hasil data yang didapat akan diuji validitasnya dengan rumus Pearson Product Moment dan uji-t serta uji Reliabilitas dengan metode alpha. Kemudian hasil pengujian akan dianalisis dengan analisis deskriptif dan analisis jalur (path analysis). Kemudian pengujian hipotesis statistik menggunakan koefisien jalur dengan uji $\mathrm{F}$ dan uji t.

\section{PEMBAHASAN}

Pembahasan ini diperoleh berdasarkan hasil kuesioner yang telah disebar kepada karyawan RS Syariah Kab Sumedang. Laporan ini akan dibagi menjadi 3 (tiga) bagian yaitu analisis demografi, analisis deskriptif dan tingkat pengaruh antar variabel.

\subsection{Demografi}

\subsubsection{Jenis Kelamin}

Berdasarkan data pada Gambar 4.1 dapat dilihat bahwa mayoritas karyawan di RS Syariah Kab Sumedang adalah Perempuan sebesar 91\% dan laki-laki 9\%. Adanya ketidak seimbangan ini dapat mengakibatkan kinerja dan kondisi perusahaan menjadi tidak optimal. Data Badan Pusat Statistik tahun 2016 menunjukan bahwa jasa kesehatan dan kegiatan sosial didominasi oleh Perempuan sebesar 67,7\% dan laki-laki 32,4\%. Hal ini perlu menjadi bahan pertimbangan dan kajian kembali meskipun setiap gender memiliki kelebihan dan kekurangan, seperti dalam hal cara berfikir, cara penyampaian, pendekatan penyelesaian masalah, ekspresi perasaan, dan lain-lain.

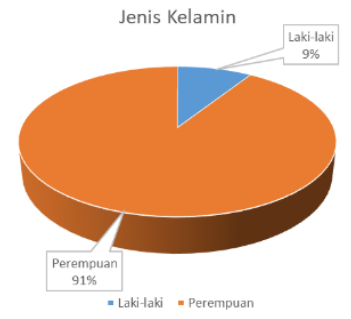

Gambar 4.1. Persentase Jenis Kelamin Karyawan di RS Syariah Kab Sumedang Sumber: Data diolah Tim Peneliti

\subsubsection{Status Pernikahan}

Karyawan RS Syariah Kab Sumedang didominasi oleh karyawan yang belum menikah sebesar 56\% dan yang telah menikah sebesar 44\%. Untuk dapat memotivasi karyawan dalam bekerja, perusahaan dapat membuat suatu aturan mengenai pemberian tunjangan keluarga pada masing-masing karyawan yang telah menikah.

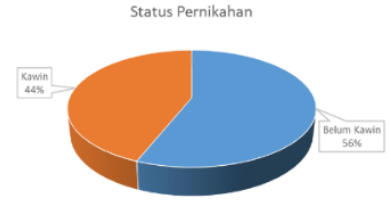

Gambar 4.2. Persentase Status Pernikahan Karyawan di RS Syariah Kab Sumedang Sumber: Data diolah Tim Peneliti 


\subsubsection{Usia}

Dengan memperhatikan sebaran usia seperti yang ditunjukkan oleh Gambar 4.3., karyawan RS Syariah Kab Sumedang berada pada $100 \%$ usia produktif, dengan didominasi oleh usia 18-25 tahun sebesar 64\%, dalam rentang usia ini para karyawan masih memerlukan proses pengarahan dan bimbingan dari kepala bidang dengan lebih intens karena kaitannya dengan pengalaman kerja yang belum lama.

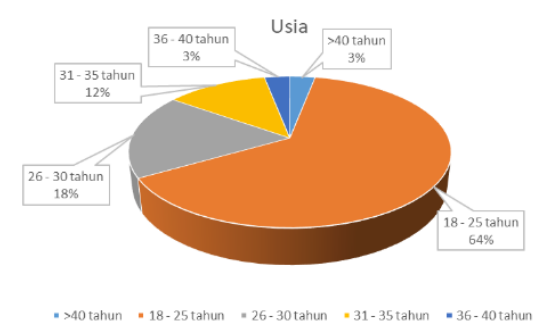

Gambar 4.3. Persentase Usia Karyawan di RS Syariah Kab Sumedang Sumber: Data diolah Tim Peneliti

\subsubsection{Tingkat Pendapatan}

Berdasarkan data pada Gambar 4.4, 95,45\% dari keseluruhan karyawan yang bekerja di RS Syariah Kab Sumedang memiliki tingkat pendapatan pada rentang Rp. 1.000.000 - Rp. 2.500.000. Berdasarkan sebaran karyawan dan merujuk pada Keputusan Gubernur Jawa Barat no. 561/ Kep.1065-Yanbangsos/ 2017 tentang upah minimum Kabupaten/Kota di daerah provinsi Jawa Barat tahun 2018, UMK untuk wilayah Kab. Bandung Rp. 2.678.029, Kab Sumedang Rp. 2.678.028, Kota Bandung Rp. 3.091.346, dan Kab. Garut Rp. 1.672.948. Posisi perusahaan berada di wilayah Kab Sumedang maka berdasarkan keputusan Gubernur tersebut sekurang-kurangnya karyawan dapat diberikan pendapatan sebesar Rp. 2.678.028,00. Untuk saat ini sebesar 95,45\% karyawan memiliki pendapatan dibawah UMK.

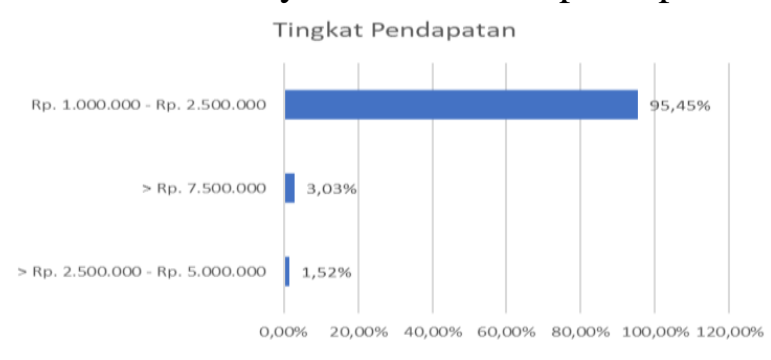

Gambar 4.4. Tingkat Pendapatan Karyawan di RS Syariah Kab Sumedang Sumber: Data diolah Tim Peneliti

\subsubsection{Tingkat Pendidikan}

Sebagian besar Karyawan RS Syariah Kab Sumedang memiliki tingkat pendidikan diploma (D1-D3) 42,42\%, diikuti Sarjana S1 24,24\% dan 1,52\% sudah menempuh pendidikan Master S2. Total karyawan yang telah mengikuti studi perguruan tinggi adalah $68,18 \%$. Perusahaan dapat melakukan investasi pada karyawan dengan cara memberikan beasiswa atau pelatihan bagi para karyawan terbaik, untuk dapat mengoptimalisasi peran dan kinerja pada RS Syariah Kab Sumedang, hal ini perlu dilakukan untuk menciptakan loyalitas pada perusahaan karena setiap karyawan harus merasakan adanya perhatian, perbaikan dan jenjang karir maupun kehidupan yang terus berkembang. 
Jurnal Manajemen dan Bisnis: Performa Volume XV Nomor 2 September 2018

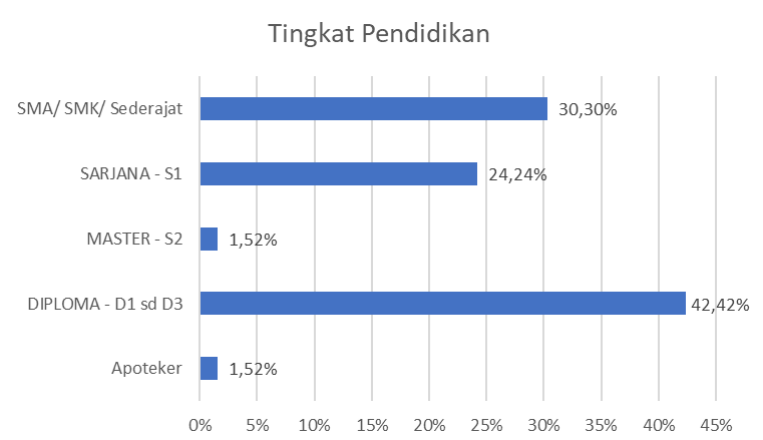

Gambar 4.5. Tingkat Pendidikan Karyawan di RS Syariah Kab Sumedang

Sumber: Data diolah Tim Peneliti

\subsubsection{Pengalaman Bekerja}

Dari hasil sebaran pengalaman kerja pada Gambar 4.5, terlihat bahwa sebesar 50\% karyawan memiliki lama kerja antara $1-3$ tahun dan $<1$ tahun sebesar 30\%. Hanya sebesar $20 \%$ karyawan yang telah memiliki pengalaman kerja lebih dari 3 tahun pada bidangnya masing-masing.

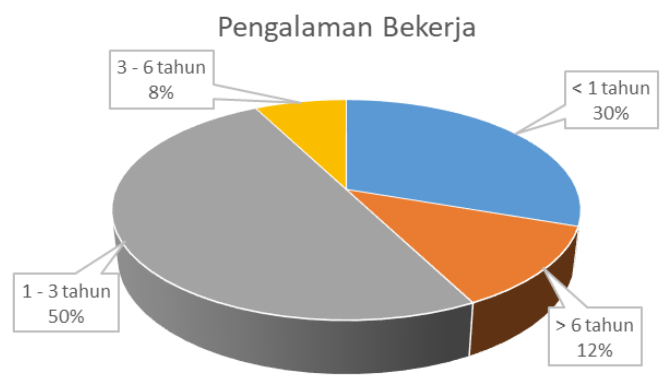

Gambar 4.6. Persentase Pengalaman Bekerja Karyawan di RS Syariah Kab Sumedang

Sumber: Data diolah Tim Peneliti

\subsubsection{Jenis Pelatihan}

Berikut ini merupakan berbagai macam jenis pelatihan yang diinginkan oleh karyawan sesuai dengan bidangnya masing-masing:

Tabel 4.1. Jenis Pelatihan yang diinginkan Karyawan RS Syariah Kab Sumedang

\begin{tabular}{|l|l|}
\hline No & \multicolumn{1}{|c|}{ Jenis Pelatihan } \\
\hline 1 & Accounting \\
\hline 2 & ACLS BCLS \\
\hline 3 & Asuhan persalinan normal \\
\hline 4 & ATCLS \\
\hline 5 & Baby spa \\
\hline 6 & BTCLS \\
\hline 7 & Cara Mencuci Baju Medis Yang Aman \\
\hline 8 & ENIL \\
\hline 9 & Hemodialisa \\
\hline 10 & Intensive Care Unit \\
\hline 11 & Kesehatan \\
\hline 12 & Kodifikasi penyakit \\
\hline
\end{tabular}


Jurnal Manajemen dan Bisnis: Performa Volume XV Nomor 2 September 2018

\begin{tabular}{|l|l|}
\hline No & \multicolumn{1}{|c|}{ Jenis Pelatihan } \\
\hline 13 & Komputer \\
\hline 14 & Komunikasi terapeutik \\
\hline 15 & Manajemen kamar operasi \\
\hline 16 & Midwifery update (MU) \\
\hline 17 & NCP \\
\hline 18 & Pelatihan ADM RUMAH SAKIT \\
\hline 19 & Pelatihan administrasi rawat jalan \\
\hline 20 & Pelatihan BPJS \\
\hline 21 & Pelatihan farmasi \\
\hline 22 & Pelatihan kamar bedah \\
\hline 23 & Pelatihan keuangan \\
\hline 24 & Pelatihan Manajemen Rekam Medis dan Pelayanan Kesehatan \\
\hline 25 & Pelatihan pengarsipan \\
\hline 26 & Pelatihan PONEK dan PPGDON \\
\hline 27 & Pelatihan tanggap darurat tenaga farmasi \\
\hline 28 & Pelayanan \\
\hline 29 & Pelayanan dan pengarsipan berkas-berkas administrasi \\
\hline 30 & Penanganan kegawat daruratan \\
\hline 31 & Pengelolaan Manajemen Rumah Sakit \\
\hline 32 & Pengelolaan Bagian Umum (rumah tangga) \\
\hline 33 & Peningkatan Mutu Pelayanan untuk Memenuhi Kepuasan Pasien \\
\hline 34 & PPR (program proteksi radiasi) \\
\hline 35 & Resusitasi neonatus \\
\hline 36 & Service excellence dan Leadership \\
\hline 37 & Syariah dan Islami \\
\hline 38 & Tata cara melayani jenis diet pasien sesuai dengan diagnosa pasien \\
\hline
\end{tabular}

Sumber: Data diolah Tim Peneliti

\subsubsection{Tabulasi data Usia dengan Pengalaman Kerja}

Tabel 4.2. Usia vs Pengalaman Kerja

\begin{tabular}{|c|c|c|c|c|c|}
\hline Usia vs Pengalaman Kerja & $<\mathbf{1}$ tahun & $>\mathbf{6}$ tahun & $\mathbf{1}-\mathbf{3}$ tahun & $\mathbf{3}-\mathbf{6}$ tahun & Grand Total \\
\hline$>40$ tahun & & 2 & & & $\mathbf{2}$ \\
\hline $18-25$ tahun & 14 & 1 & 24 & 3 & $\mathbf{4 2}$ \\
\hline $26-30$ tahun & 2 & 1 & 7 & 2 & $\mathbf{1 2}$ \\
\hline $31-35$ tahun & 3 & 3 & 2 & & $\mathbf{8}$ \\
\hline $36-40$ tahun & 1 & 1 & & & $\mathbf{2}$ \\
\hline Grand Total & $\mathbf{2 0}$ & $\mathbf{8}$ & $\mathbf{3 3}$ & $\mathbf{5}$ & $\mathbf{6 6}$ \\
\hline
\end{tabular}

Sumber: Data diolah Tim Peneliti

Dari Tabel 4.2. dapat diketahui bahwa usia karyawan rata-rata di RS Syariah Kab Sumedang adalah 18-25 tahun yang sebagian besar memiliki pengalaman antara 1-3 tahun, sehingga masih diperlukan pendampingan, pengawasan, dan pemberian pelatihan yang tepat agar para karyawan menjadi sosok kekuatan dalam organisasi. 


\subsubsection{Tabulasi data tingkat Pendidikan dengan Latar belakangnya}

Tabel 4.3. Data Tingkat Pendidikan vs Latar belakang keilmuan

\begin{tabular}{|l|c|c|c|c|c|c|}
\hline \multicolumn{1}{|c|}{ Pendidikan vs Latar Belakang } & Apoteker & D1 - D3 & S2 & S1 & SMA/K & Total \\
\hline Administrasi perkantoran & & & & & 3 & $\mathbf{3}$ \\
\hline Apoteker & 1 & & & & & $\mathbf{1}$ \\
\hline Asisten apoteker & & & & & 2 & $\mathbf{2}$ \\
\hline Business Management & & & 1 & & & $\mathbf{1}$ \\
\hline Ekonomi & & & & 5 & 3 & $\mathbf{8}$ \\
\hline Farmasi & & & & 1 & 4 & $\mathbf{5}$ \\
\hline Gizi & & 8 & & 2 & & $\mathbf{1 0}$ \\
\hline Kebidanan & & & & & 1 & $\mathbf{1}$ \\
\hline Keuangan & & & & & 1 & $\mathbf{1}$ \\
\hline Linen (laundry) & & & & & 2 & $\mathbf{2}$ \\
\hline MA IPA & & & & & 1 & $\mathbf{1}$ \\
\hline Non medis & & 13 & & 6 & & $\mathbf{1 9}$ \\
\hline Perawat & & 3 & & 1 & & $\mathbf{4}$ \\
\hline Rekam Medis dan Informasi Kesehatan & & 2 & & & & $\mathbf{2}$ \\
\hline Radiodiagnostik dan radioterapi & & & & & 1 & $\mathbf{1}$ \\
\hline Sains & & 1 & & & & $\mathbf{1}$ \\
\hline Sanitarian & & & & & 1 & $\mathbf{1}$ \\
\hline SMK informatika & & & & 1 & & $\mathbf{1}$ \\
\hline Sosial & & & & & 1 & $\mathbf{1}$ \\
\hline Tata boga & $\mathbf{1}$ & $\mathbf{2 8}$ & $\mathbf{1}$ & $\mathbf{1 6}$ & $\mathbf{2 0}$ & $\mathbf{6 6}$ \\
\hline
\end{tabular}

Sumber: Data diolah Tim Peneliti

Tabel 4.3. menunjukkan bahwa tingkat pendidikan D1-D3 adalah yang terbanyak dengan latar belakang sebagai Perawat. Selanjutnya karyawan lulusan SMA/SMK terbanyak pada bidang Administrasi, Farmasi, dan Ekonomi.

\subsection{Analisis Deskriptif}

Dibawah ini merupakan analisis deskriptif dari pengolahan kuesioner yang telah diolah. Dari total 47 pernyataan yang dinilai terbagi menjadi dua bagian, pertama mengenai budaya organisasi islami sebanyak 40 pernyataan dan kedua mengenai efektifitas penerapan budaya sebanyak 7 pernyataan.

\subsubsection{Budaya Organisasi Islami}

Berdasarkan Tabel 4.4., terdapat penilaian "baik sekali" terhadap 11 (sebelas) pernyataan dan sebanyak 29 pernyataan lainnya memiliki penilaian "baik" yang ditanyakan kepada para responden yaitu karyawan RS Syariah Kab Sumedang. Dari 29 (dua puluh sembilan) pernyataan yang memiliki penilaian "baik" terdapat 22 (dua puluh dua) pernyataan yang memiliki nilai dibawah rata-rata 202. Hal itu memberi arti bahwa penilaian "baik" tersebut dapat tergelincir dengan cepat jika pihak manajemen tidak dapat mengelola organisasi dengan lebih baik lagi. 
Tabel 4.4 Budaya Organisasi Islami di RS Syariah Kab Sumedang

\begin{tabular}{|c|c|c|c|c|c|c|c|}
\hline \multirow{2}{*}{ No } & \multirow{2}{*}{ Pernyataan } & \multicolumn{4}{|c|}{ Skala } & \multirow{2}{*}{ Total } & \multirow{2}{*}{ Keterangan } \\
\hline & & 1 & 2 & 3 & 4 & & \\
\hline \multirow[t]{2}{*}{1} & \multirow{2}{*}{$\begin{array}{l}\text { Beban kerja tidak menghalangi saya } \\
\text { untuk aktif mengikuti kegiatan sosial } \\
\text { kemasyarakatan dan keislaman yang } \\
\text { diadakan oleh perusahaan }\end{array}$} & 1 & 14 & 135 & 52 & 202 & BAIK \\
\hline & & $0,50 \%$ & $6,93 \%$ & $66,83 \%$ & $25,74 \%$ & & \\
\hline \multirow[t]{2}{*}{2} & \multirow{2}{*}{$\begin{array}{l}\text { Saya yakin dengan atau tanpa adanya } \\
\text { pengawasan dari atasan, teman-teman } \\
\text { karyawan tetap akan bekerja dengan } \\
\text { sungguh-sungguh }\end{array}$} & 2 & 14 & 99 & 96 & 211 & BAIK \\
\hline & & $0,95 \%$ & $6,64 \%$ & $46,92 \%$ & $45,50 \%$ & & \\
\hline \multirow[t]{2}{*}{3} & \multirow{2}{*}{$\begin{array}{l}\text { Saya senantiasa mencari } \\
\text { masukan/kritik dan saran terhadap } \\
\text { hasil kerja yang dilakukan }\end{array}$} & & 10 & 99 & 112 & 221 & BAIK SEKALI \\
\hline & & $0,00 \%$ & $4,52 \%$ & $44,80 \%$ & $50,68 \%$ & & \\
\hline \multirow[t]{2}{*}{4} & \multirow{2}{*}{$\begin{array}{l}\text { Saya memahami dan bekerja optimal } \\
\text { untuk membantu perusahaan } \\
\text { mendapatkan hasil yang terbaik }\end{array}$} & & 4 & 108 & 112 & 224 & BAIK SEKALI \\
\hline & & $0,00 \%$ & $1,79 \%$ & $48,21 \%$ & $50,00 \%$ & & \\
\hline \multirow[t]{2}{*}{5} & \multirow{2}{*}{$\begin{array}{l}\text { Saya memiliki tekad kuat untuk } \\
\text { menjadikan perusahaan sebagai } \\
\text { lokomotif gerakan sehat di masyarakat }\end{array}$} & & 6 & 135 & 72 & 213 & BAIK \\
\hline & & $0,00 \%$ & $2,82 \%$ & $63,38 \%$ & $33,80 \%$ & & \\
\hline \multirow[t]{2}{*}{6} & \multirow{2}{*}{$\begin{array}{l}\text { Saya tidak pernah memanipulasi hasil } \\
\text { kerja untuk memuaskan Pimpinan }\end{array}$} & & 4 & 93 & 132 & 229 & BAIK SEKALI \\
\hline & & $0,00 \%$ & $1,75 \%$ & $40,61 \%$ & $57,64 \%$ & & \\
\hline \multirow[t]{2}{*}{7} & \multirow{2}{*}{$\begin{array}{l}\text { Saya ingin tumbuh dan berkembang } \\
\text { bersama perusahaan }\end{array}$} & 1 & 8 & 108 & 100 & 217 & BAIK SEKALI \\
\hline & & $0,46 \%$ & $3,69 \%$ & $49,77 \%$ & $46,08 \%$ & & \\
\hline \multirow[t]{2}{*}{8} & \multirow{2}{*}{$\begin{array}{l}\text { Saya sabar untuk mengatasi berbagai } \\
\text { permasalahan yang ada dalam } \\
\text { perusahaan }\end{array}$} & & 10 & 138 & 60 & 208 & BAIK \\
\hline & & $0,00 \%$ & $4,81 \%$ & $66,35 \%$ & $28,85 \%$ & & \\
\hline \multirow[t]{2}{*}{9} & \multirow{2}{*}{$\begin{array}{l}\text { Saya memaksimalkan seluruh } \\
\text { kemampuan untuk memberikan yang } \\
\text { terbaik }\end{array}$} & & 4 & 120 & 96 & 220 & BAIK SEKALI \\
\hline & & $0,00 \%$ & $1,82 \%$ & $54,55 \%$ & $43,64 \%$ & & \\
\hline \multirow[t]{2}{*}{10} & \multirow{2}{*}{$\begin{array}{l}\text { Saya bekerja secara profesional dan } \\
\text { bertanggung jawab sesuai pekerjaan }\end{array}$} & & 2 & 117 & 104 & 223 & BAIK SEKALI \\
\hline & & $0,00 \%$ & $0,90 \%$ & $52,47 \%$ & $46,64 \%$ & & \\
\hline \multirow[t]{2}{*}{11} & Saya berusaha meninggalkan & & 4 & 99 & 124 & 227 & BAIK SEKALI \\
\hline & $\begin{array}{l}\text { kebiasaan buruk untuk kemudian } \\
\text { diganti dengan kebiasaan baik }\end{array}$ & $0,00 \%$ & $1,76 \%$ & $43,61 \%$ & $54,63 \%$ & & \\
\hline 12 & Perusahaan turut membantu dalam & 1 & 22 & 123 & 52 & 198 & BAIK \\
\hline & $\begin{array}{l}\text { pengembangan keahlian dan keilmuan } \\
\text { saya }\end{array}$ & $0,51 \%$ & $11,11 \%$ & $62,12 \%$ & $26,26 \%$ & & \\
\hline 13 & Saya konsisten dan selalu melakukan & & 2 & 138 & 76 & 216 & BAIK SEKALI \\
\hline & $\begin{array}{l}\text { perbaikan terus menerus terhadap hasil } \\
\text { kerja }\end{array}$ & $0,00 \%$ & $0,93 \%$ & $63,89 \%$ & $35,19 \%$ & & \\
\hline 14 & Saya tidak menganggap diri saya lebih & 1 & 6 & 108 & 104 & 219 & BAIK SEKALI \\
\hline & baik dibandingkan karyawan lainnya & $0,46 \%$ & $2,74 \%$ & $49,32 \%$ & $47,49 \%$ & & \\
\hline 15 & Saya bekerja sesuai dengan waktu & & 12 & 120 & 80 & 212 & BAIK \\
\hline & yang telah ditetapkan secara teratur & $0,00 \%$ & $5,66 \%$ & $56,60 \%$ & $37,74 \%$ & & \\
\hline 16 & Saya taat pada setiap Instruksi & & 6 & 147 & 56 & 209 & BAIK \\
\hline & pimpinan & $0,00 \%$ & $2,87 \%$ & $\mathbf{7 0 , 3 3 \%}$ & $26,79 \%$ & & \\
\hline 17 & Saya senang mencoba menerapkan ide & & 2 & 141 & 72 & 215 & BAIK SEKALI \\
\hline & $\begin{array}{l}\text { baru untuk mempercepat dan } \\
\text { mengefektifkan pekerjaan yang sedang } \\
\text { dilakukan }\end{array}$ & $0,00 \%$ & $0,93 \%$ & $65,58 \%$ & $33,49 \%$ & & \\
\hline 18 & Saya senang berpenampilan islami & & 6 & 120 & 92 & 218 & BAIK SEKALI \\
\hline & (sesuai sunnah) & $0,00 \%$ & $2,75 \%$ & $55,05 \%$ & $42,20 \%$ & & \\
\hline 19 & Karyawan terbiasa untuk saling & & 10 & 132 & 68 & 210 & BAIK \\
\hline
\end{tabular}




\begin{tabular}{|c|c|c|c|c|c|c|c|}
\hline \multirow{2}{*}{ No } & \multirow{2}{*}{ Pernyataan } & \multicolumn{4}{|c|}{ Skala } & \multirow{2}{*}{ Total } & \multirow{2}{*}{ Keterangan } \\
\hline & & 1 & 2 & 3 & 4 & & \\
\hline & mengingatkan dan menasehati & $0,00 \%$ & $4,76 \%$ & $62,86 \%$ & $32,38 \%$ & & \\
\hline \multirow[t]{2}{*}{20} & \multirow{2}{*}{$\begin{array}{l}\text { Kerja sama karyawan antar unit sudah } \\
\text { berjalan dengan baik }\end{array}$} & 3 & 36 & 126 & 12 & 177 & BAIK \\
\hline & & $1,69 \%$ & $20,34 \%$ & $71,19 \%$ & $6,78 \%$ & & \\
\hline \multirow[t]{2}{*}{21} & \multirow{2}{*}{$\begin{array}{l}\text { Karyawan terbiasa berbicara santun } \\
\text { dan saling menghargai terhadap rekan } \\
\text { kerjanya }\end{array}$} & 1 & 18 & 132 & 48 & 199 & BAIK \\
\hline & & $0,50 \%$ & $9,05 \%$ & $66,33 \%$ & $24,12 \%$ & & \\
\hline \multirow[t]{2}{*}{22} & \multirow{2}{*}{$\begin{array}{l}\text { Pelayanan yang diberikan karyawan } \\
\text { terhadap konsumen sudah optimal }\end{array}$} & & 12 & 138 & 56 & 206 & BAIK \\
\hline & & $0,00 \%$ & $5,83 \%$ & $66,99 \%$ & $27,18 \%$ & & \\
\hline \multirow[t]{2}{*}{23} & \multirow{2}{*}{$\begin{array}{l}\text { Karyawan terbiasa untuk mencari } \\
\text { penjelasan terhadap informasi yang } \\
\text { belum jelas kebenarannya }\end{array}$} & & 12 & 132 & 64 & 208 & BAIK \\
\hline & & $0,00 \%$ & $5,77 \%$ & $63,46 \%$ & $30,77 \%$ & & \\
\hline \multirow[t]{2}{*}{24} & \multirow{2}{*}{$\begin{array}{l}\text { Karyawan tidak suka membicarakan } \\
\text { karyawan lain dibelakangnya }\end{array}$} & 5 & 30 & 99 & 52 & 186 & BAIK \\
\hline & & $2,69 \%$ & $16,13 \%$ & $53,23 \%$ & $27,96 \%$ & & \\
\hline \multirow[t]{2}{*}{25} & \multirow{2}{*}{$\begin{array}{l}\text { Tidak ada karyawan yang dengki } \\
\text { terhadap kesuksesan seseorang (rekan } \\
\text { kerja) }\end{array}$} & 3 & 16 & 132 & 44 & 195 & BAIK \\
\hline & & $1,54 \%$ & $8,21 \%$ & $67,69 \%$ & $22,56 \%$ & & \\
\hline \multirow[t]{2}{*}{26} & \multirow{2}{*}{$\begin{array}{l}\text { Sebagian besar masalah diselesaikan } \\
\text { dengan mekanisme rapat yang } \\
\text { demokratis dan musyawarah }\end{array}$} & 2 & 18 & 135 & 40 & 195 & BAIK \\
\hline & & $1,03 \%$ & $9,23 \%$ & $69,23 \%$ & $20,51 \%$ & & \\
\hline \multirow[t]{2}{*}{27} & \multirow{2}{*}{$\begin{array}{l}\text { Dalam memberikan penghargaan atau } \\
\text { teguran, pimpinan tidak pernah } \\
\text { membeda-bedakan karyawan, } \\
\text { penilaian diambil berdasarkan data } \\
\text { dan informasi secara objektif }\end{array}$} & 2 & 16 & 141 & 36 & 195 & BAIK \\
\hline & & $1,03 \%$ & $8,21 \%$ & $72,31 \%$ & $18,46 \%$ & & \\
\hline \multirow[t]{2}{*}{28} & \multirow{2}{*}{$\begin{array}{l}\text { Menurut saya, pimpinan sudah layak } \\
\text { dijadikan panutan bagi karyawan }\end{array}$} & 3 & 34 & 123 & 20 & 180 & BAIK \\
\hline & & $1,67 \%$ & $18,89 \%$ & $68,33 \%$ & $11,11 \%$ & & \\
\hline \multirow[t]{2}{*}{29} & \multirow{2}{*}{$\begin{array}{l}\text { Saya melihat pimpinan selalu } \\
\text { menyelaraskan ucapan dengan } \\
\text { perbuatannya }\end{array}$} & 3 & 30 & 135 & 12 & 180 & BAIK \\
\hline & & $1,67 \%$ & $16,67 \%$ & $75,00 \%$ & $6,67 \%$ & & \\
\hline 30 & Saya rasa pimpinan tidak suka & 3 & 20 & 144 & 20 & 187 & BAIK \\
\hline & melempar tanggung jawab & $1,60 \%$ & $10,70 \%$ & $77,01 \%$ & $10,70 \%$ & & \\
\hline 31 & Menurut saya, Pimpinan memiliki & 1 & 22 & 150 & 16 & 189 & BAIK \\
\hline & $\begin{array}{l}\text { kapasitas keilmuan yang baik untuk } \\
\text { dapat menjalankan tugas yang } \\
\text { diembannya }\end{array}$ & $0,53 \%$ & $11,64 \%$ & $79,37 \%$ & $8,47 \%$ & & \\
\hline 32 & Saya merasa Pimpinan dapat & 2 & 28 & 138 & 16 & 184 & BAIK \\
\hline & $\begin{array}{l}\text { mengkomunikasikan idenya kepada } \\
\text { bawahan dengan baik }\end{array}$ & $1,09 \%$ & $15,22 \%$ & $75,00 \%$ & $8,70 \%$ & & \\
\hline 33 & Saya rasa Pimpinan senantiasa & 1 & 16 & 144 & 36 & 197 & BAIK \\
\hline & $\begin{array}{l}\text { memotivasi karyawannya untuk maju } \\
\text { bersama memperjuangkan tercapainya } \\
\text { visi organisasi }\end{array}$ & $0,51 \%$ & $8,12 \%$ & $73,10 \%$ & $18,27 \%$ & & \\
\hline 34 & Saya merasa pemimpin memiliki sifat & 2 & 22 & 147 & 16 & 187 & BAIK \\
\hline & Mu'allim (educative leadership) & $1,07 \%$ & $11,76 \%$ & $78,61 \%$ & $8,56 \%$ & & \\
\hline 35 & Menurut saya, Pimpinan sudah & 1 & 28 & 144 & 12 & 185 & BAIK \\
\hline & $\begin{array}{l}\text { menempatkan orang berdasarkan } \\
\text { kemampuannya }\end{array}$ & $0,54 \%$ & $15,14 \%$ & $\mathbf{7 7 , 8 4 \%}$ & $6,49 \%$ & & \\
\hline 36 & Menurut saya Pimpinan cekatan dalam & 3 & 32 & 135 & 8 & 178 & BAIK \\
\hline & pengambilan kebijakan dan keputusan & $1,69 \%$ & $17,98 \%$ & $75,84 \%$ & $4,49 \%$ & & \\
\hline 37 & Saya merasa Pimpinan dapat & 2 & 30 & 129 & 24 & 185 & BAIK \\
\hline & $\begin{array}{l}\text { menumbuhkan kehangatan hubungan } \\
\text { antar karyawan }\end{array}$ & $1,08 \%$ & $16,22 \%$ & $69,73 \%$ & $12,97 \%$ & & \\
\hline 38 & Menurut saya, silaturahim antara & 2 & 24 & 141 & 20 & 187 & BAIK \\
\hline & Pimpinan dan karyawan sudah baik & $1,07 \%$ & $12,83 \%$ & $75,40 \%$ & $10,70 \%$ & & \\
\hline
\end{tabular}


Jurnal Manajemen dan Bisnis: Performa Volume XV Nomor 2 September 2018

\begin{tabular}{|c|c|c|c|c|c|c|c|}
\hline \multirow{2}{*}{ No } & \multirow{2}{*}{ Pernyataan } & \multicolumn{4}{|c|}{ Skala } & \multirow{2}{*}{ Total } & \multirow{2}{*}{ Keterangan } \\
\hline & & 1 & 2 & 3 & 4 & & \\
\hline \multirow[t]{2}{*}{39} & \multirow{2}{*}{$\begin{array}{l}\text { Saya melihat Pimpinan partisipatif } \\
\text { terhadap kegiatan karyawan }\end{array}$} & 1 & 32 & 138 & 12 & 183 & BAIK \\
\hline & & $0,55 \%$ & $17,49 \%$ & $75,41 \%$ & $6,56 \%$ & & \\
\hline \multirow[t]{2}{*}{40} & \multirow{2}{*}{$\begin{array}{l}\text { Saya merasa Pimpinan mendorong } \\
\text { karyawan untuk melakukan } \\
\text { penghematan dalam bekerja }\end{array}$} & 1 & 18 & 147 & 28 & 194 & BAIK \\
\hline & & $0,52 \%$ & $9,28 \%$ & $\mathbf{7 5 , 7 7 \%}$ & $14,43 \%$ & & \\
\hline \multicolumn{6}{|c|}{ Rata-rata } & 202 & BAIK \\
\hline
\end{tabular}

Sumber: Data diolah Tim Peneliti

Dari hal tersebut diatas dibahas 13 (tiga belas) prioritas utama yang harus dikelola dengan lebih baik lagi oleh manajemen, pada Tabel 4.5.

Tabel 4.5. Prioritas Utama yang harus diperbaiki Manajemen RS Syariah Kab Sumedang

\begin{tabular}{|c|c|c|c|}
\hline No & & Pernyataan & Rekomendasi \\
\hline 1 & 20 & $\begin{array}{l}\text { Kerjasama karyawan antar unit } \\
\text { sudah berjalan dengan baik }\end{array}$ & $\begin{array}{l}\text { Perusahaan perlu melakukan training and } \\
\text { workshop mengenai character building and } \\
\text { teamwork, lebih baik dilakukan dalam suasana } \\
\text { outdoor berupa gathering. }\end{array}$ \\
\hline 2 & 36 & $\begin{array}{l}\text { Menurut saya Pimpinan cekatan } \\
\text { dalam pengambilan kebijakan dan } \\
\text { keputusan }\end{array}$ & $\begin{array}{l}\text { Pimpinan perlu melakukan skala prioritas utama } \\
\text { terhadap pekerjaan yang dilakukan dan diingatkan } \\
\text { kembali oleh pihak manajerial yang ada. }\end{array}$ \\
\hline 3 & 28 & $\begin{array}{l}\text { Menurut saya, pimpinan sudah } \\
\text { layak dijadikan panutan bagi } \\
\text { karyawan }\end{array}$ & $\begin{array}{l}\text { Pimpinan perlu diberikan masukan oleh PT } \\
\text { berdasarkan data. }\end{array}$ \\
\hline 4 & 29 & $\begin{array}{llr}\begin{array}{l}\text { Saya melihat } \\
\text { menyelaraskan } \\
\text { perbuatannya }\end{array} & \begin{array}{l}\text { pimpinan } \\
\text { ucapan }\end{array} & \text { selalu } \\
\text { dengan }\end{array}$ & $\begin{array}{l}\text { Pimpinan perlu diberikan masukan oleh PT } \\
\text { berdasarkan data. }\end{array}$ \\
\hline 5 & 39 & $\begin{array}{l}\text { Saya melihat Pimpinan partisipatif } \\
\text { terhadap kegiatan karyawan }\end{array}$ & $\begin{array}{l}\text { Meningkatkan peran saling menghargai antar } \\
\text { anggota organisasi }\end{array}$ \\
\hline 6 & 32 & $\begin{array}{l}\text { Saya merasa Pimpinan dapat } \\
\text { mengkomunikasikan idenya kepada } \\
\text { bawahan dengan baik }\end{array}$ & $\begin{array}{l}\text { Pimpinan dapat membentuk tim change agent } \\
\text { dengan perwakilan dari tiap bidang untuk dapat } \\
\text { membumikan visi dan tujuan perusahaan }\end{array}$ \\
\hline 7 & 35 & $\begin{array}{l}\text { Menurut saya, Pimpinan sudah } \\
\text { menempatkan orang berdasarkan } \\
\text { kemampuannya }\end{array}$ & $\begin{array}{l}\text { Pimpinan dan manajerial perlu melakukan } \\
\text { pengkajian kembali terhadap orang-orang yang } \\
\text { memang memiliki kompetensi pada bidangnya, } \\
\text { sehingga perlu diterapkan promosi, rotasi, demosi } \\
\text { dan pemutusan hubungan kerja. } \\
\text { Hal ini perlu dilakukan karena menyangkut cost } \\
\text { efficiency yang menjadi fokus dalam organisasi. }\end{array}$ \\
\hline 8 & 37 & $\begin{array}{l}\text { Saya merasa Pimpinan dapat } \\
\text { menumbuhkan } \\
\text { hubungan antar karyawan }\end{array}$ & $\begin{array}{l}\text { Perusahaan dapat membuat suatu kebijakan yang } \\
\text { dapat menumbuhkan rasa persaudaraan semakin } \\
\text { kuat, seperti taklim, olahraga rutin, dll. }\end{array}$ \\
\hline 9 & 24 & $\begin{array}{l}\text { Karyawan tidak suka membicarakan } \\
\text { karyawan lain dibelakangnya }\end{array}$ & $\begin{array}{l}\text { Membicarakan seseorang di "belakang" } \\
\text { menandakan bahwa adanya pola/sistem yang tidak } \\
\text { berjalan dengan baik. Kemungkinan terjadinya } \\
\text { kecemburuan sosial dan ketidakadilan yang } \\
\text { berlaku dalam organisasi, oleh karena itu } \\
\text { perusahaan harus dapat membuat suatu penilaian } \\
\text { kinerja masing-masing karyawan, sehingga } \\
\text { reward dan punishment yang diberikan terukur }\end{array}$ \\
\hline
\end{tabular}


Jurnal Manajemen dan Bisnis: Performa Volume XV Nomor 2 September 2018

\begin{tabular}{|c|c|c|c|}
\hline No & \multicolumn{2}{|r|}{ Pernyataan } & Rekomendasi \\
\hline & & & oleh setiap karyawan. \\
\hline 10 & 30 & $\begin{array}{l}\text { Saya rasa pimpinan tidak suka } \\
\text { melempar tanggung jawab }\end{array}$ & $\begin{array}{l}\text { Pemimpin yang suka melempar tanggung jawab } \\
\text { pada anak buahnya sudah jelas dia bukan tipikal } \\
\text { seorang pemimpin. } \\
\text { Pemimpin harus bertanggung jawab pada setiap } \\
\text { pekerjaan yang dikerjakan oleh seluruh anggota } \\
\text { organisasi. }\end{array}$ \\
\hline 11 & 34 & $\begin{array}{l}\text { Saya merasa pemimpin memiliki } \\
\text { sifat } \quad \text { Mu'allim } \\
\text { leadership) }\end{array}$ & $\begin{array}{l}\text { Seorang pemimpin harus dapat tampil dan } \\
\text { menyampaikan ilmu yang dimilikinya kepada } \\
\text { para anggota organisasi. Baik itu kajian agama } \\
\text { maupun berupa pelatihan internal yang diadakan } \\
\text { oleh pimpinan itu sendiri. }\end{array}$ \\
\hline 12 & 38 & $\begin{array}{l}\text { Menurut saya, silaturahim antara } \\
\text { Pimpinan dan karyawan sudah baik }\end{array}$ & $\begin{array}{l}\text { Peningkatan silaturahim antara pimpinan dan } \\
\text { karyawan dalam hal-hal yang bersifat non formal, } \\
\text { dapat dimulai dengan merubah panggilan } \\
\text { keseharian untuk membuat keakraban semakin } \\
\text { terasa. } \\
\text { Contoh: Panggilan Bapak digantikan oleh akang, } \\
\text { Ibu digantikan oleh teteh, dll. }\end{array}$ \\
\hline 13 & 43 & $\begin{array}{l}\text { Saya merasa keterbukaan terbangun } \\
\text { dengan baik antar karyawan }\end{array}$ & $\begin{array}{l}\text { Keterbukaan terbangun dengan adanya rasa } \\
\text { percaya dari masing-masing anggota organisasi, } \\
\text { rasa percaya ini timbul bila masing-masing } \\
\text { anggota organisasi dapat saling mengenal secara } \\
\text { mendalam satu sama lainnya sehingga rasa empati } \\
\text { yang tercipta. } \\
\text { Salah satu cara untuk menciptakan rasa tersebut } \\
\text { adalah dengan melakukan family gathering. }\end{array}$ \\
\hline
\end{tabular}

Sumber: Data diolah Tim Peneliti

\subsubsection{Efektifitas Penerapan Budaya}

Tabel 4.6. Efektifitas Penerapan Budaya

\begin{tabular}{|c|c|c|c|c|c|c|c|}
\hline \multirow{2}{*}{ No } & \multirow{2}{*}{ Pernyataan } & \multicolumn{4}{|c|}{ Skala } & \multirow{2}{*}{ Total } & \multirow{2}{*}{ Keterangan } \\
\hline & & 1 & 2 & 3 & 4 & & \\
\hline \multirow[t]{2}{*}{41} & \multirow{2}{*}{$\begin{array}{l}\text { Sarana dan prasarana pendukung } \\
\text { pekerjaan, sudah tersedia dan } \\
\text { memudahkan bagi karyawan }\end{array}$} & 7 & 54 & 84 & 16 & 161 & BURUK \\
\hline & & $4,35 \%$ & $33,54 \%$ & $52,17 \%$ & $9,94 \%$ & & \\
\hline \multirow[t]{2}{*}{42} & \multirow{2}{*}{$\begin{array}{l}\text { Karyawan diberikan waktu yang cukup } \\
\text { untuk melaksanakan sholat }\end{array}$} & 2 & 14 & 120 & 68 & 204 & BAIK \\
\hline & & $0,98 \%$ & $6,86 \%$ & $58,82 \%$ & $33,33 \%$ & & \\
\hline \multirow[t]{2}{*}{43} & \multirow{2}{*}{$\begin{array}{l}\text { Saya merasa keterbukaan terbangun } \\
\text { dengan baik antar karyawan }\end{array}$} & 2 & 26 & 132 & 28 & 188 & BAIK \\
\hline & & $1,06 \%$ & $13,83 \%$ & $70,21 \%$ & $14,89 \%$ & & \\
\hline \multirow[t]{2}{*}{44} & \multirow{2}{*}{$\begin{array}{l}\text { Setiap karyawan memahami perannya } \\
\text { dalam organisasi }\end{array}$} & & 26 & 144 & 20 & 190 & BAIK \\
\hline & & $0,00 \%$ & $13,68 \%$ & $75,79 \%$ & $10,53 \%$ & & \\
\hline \multirow[t]{2}{*}{45} & \multirow{2}{*}{$\begin{array}{l}\text { Saya yakin karyawan yang absen bekerja } \\
\text { memberikan alasan yang jelas dan dapat } \\
\text { dipertanggungjawabkan }\end{array}$} & & 6 & 144 & 60 & 210 & BAIK \\
\hline & & $0,00 \%$ & $2,86 \%$ & $68,57 \%$ & $28,57 \%$ & & \\
\hline \multirow[t]{2}{*}{46} & \multirow{2}{*}{$\begin{array}{l}\text { Saya merasa pergantian karyawan jarang } \\
\text { terjadi }\end{array}$} & 9 & 36 & 105 & 16 & 166 & BAIK \\
\hline & & $5,42 \%$ & $21,69 \%$ & $63,25 \%$ & $9,64 \%$ & & \\
\hline \multirow[t]{2}{*}{47} & \multirow{2}{*}{$\begin{array}{l}\text { Saya merasa konflik antar karyawan } \\
\text { jarang terjadi }\end{array}$} & 7 & 42 & 96 & 24 & 169 & BAIK \\
\hline & & $4,14 \%$ & $24,85 \%$ & $56,80 \%$ & $14,20 \%$ & & \\
\hline \multicolumn{6}{|c|}{ Rata-rata } & 184 & BAIK \\
\hline
\end{tabular}

Sumber: Data diolah Tim Peneliti 


\section{KESIMPULAN DAN SARAN}

\subsection{Kesimpulan}

Berdasarkan pembahasan dalam melakukan serangkaian pengumpulan data, pengolahan data, penyebaran kuesioner dan pengujian hipotesis dengan tujuan mengetahui dan menganalisis efektivitas penerapan budaya organisasi terhadap efektivitas organisasi, maka dapat diambil kesimpulan budaya organisasi yang dirasakan pada RS Syariah Kab Sumedang dalam kategori kuat serta efektivitas organisasi dalam kategori yang baik. Bila dilihat berdasarkan dimensi budaya organisasi yang digunakan, maka nilai Islam yang ada pada masing-masing perilaku individu, perilaku antar individu serta perilaku kepemimpinan di dalamnya secara positif membentuk budaya organisasi Islami di RS Syariah Kab Sumedang. Ada beberapa hal yang harus diperhatikan oleh manajemen RS Syariah Kab Sumedang terkait dengan penerapan budaya organisasinya agar dapat berjalan lebih baik lagi.

\subsection{Saran}

Hasil perhitungan dan analisa menunjukkan bahwa efektifitas kerja RS Syariah Kab Sumedang secara keseluruhan telah berjalan dengan baik meskipun masih terdapat beberapa catatan penting untuk dapat dibenahi, seperti:

1. Manajemen harus menganggap pemenuhan sarana dan prasarana sebagai suatu investasi jangka panjang untuk meningkatkan kenyamanan dan keefektifan bekerja, sehingga ketika karyawan diberi target tugas dapat dikerjakan dengan cepat dan lancar.

2. Perlu menjadi perhatian manajemen apakah human resource yang ada saat ini akan ditetapkan sebagai human capital atau hanya sebagai karyawan biasa yang hanya sebatas bekerja sesuai SOP yang ditetapkan. Pihak manajemen harus mencari tahu alasan mengapa para karyawan resign dari RS Syariah Kab Sumedang, informasi dapat didapatkan dari hasil wawancara terakhir sebelum resmi diberikan surat pemberhentian kerja.

3. Penyebab konflik yang ada saat ini harus dapat ditelusuri dengan cara melakukan wawancara secara random sampling kepada karyawan agar konflik yang ada dapat dikontrol dan tidak semakin membesar yang dapat mengakibatkan suasana kerja menjadi tidak kondusif dan pasien atau calon pasien dapat menjadi korban dari keadaan tersebut, bila hal itu telah terjadi dikhawatirkan adanya WOM negatif yang viral di media sosial.

\section{DAFTAR PUSTAKA}

Adityangga, Krishna. 2010. Membangun perusahaan Islam : Dengan manajemen budaya perusahaan islami-Islamic Corporate Culture Management. Jakarta: Raja Grafindo Persada

Adnanputra, AS. 1999. Nilai-nilai Islam dan Budaya corporat, dalam effendi, et.el. Nilai dan Makna Kerja Dalam Islam. Jakarta : Nuansa madani.

Alamsyah. 2002. Pengembangan Konsep dan Instrument Budaya Organisasi Islam untuk Rumah Sakit Bernafaskan Islam. Tesis, Program Pasca Sarjana FKM UI. Depok. 
Hakim, Abdul. 2012. "The Implementation of Islamic Leadership and Islamic Organizational Culture and Its Influence on Islamic Working Motivation and Islamic Performance PT Bank Mu." Asia Pacific Management Review 17.1: 77-90.

Khaliq, Ahmad. 2007. Management form Islamic Perspective. Pearson Custom Publishing ISBN:978-967-349-070-7.

Mangkunegara. 2003. Perencanaan Dan Pengembangan Sumber Daya Manusia. Bandung : PT Refika Aditama

Qardhawi, Yusuf. (1995). Daurul Qiyam wal Akhlaq fil Iqtishodil Islami, First Edition, Maktabah Wahbah, Kairo, Mesir. Hafidhuddin, Utomo, Tamhid (penerjemah, 1997). Peran Nilai dan Moral dalam Perekonomian Islam. Cetakan pertama. Robbani Press, Jakarta.

Rivai, Veithzal. 2006. Manajemen Sumber Daya Manusia Untuk Perusahaan: Dari Teori Ke Praktik. Jakarta: PT. Raja Grafindo Persada

Robbins, S.P. 2002. Perilaku Organisasi, Konsep, Kontroversi, Aplikasi, Jilid II, Edisi Bahasa Indonesia, Alih Bahasa Hadyana Pujaatmaka. Jakarta: Prenhalindo. 